\title{
Comorbidities as Risk Factors for Mortality in COVID-19 Acute Respiratory Distress Syndrome Adult Patients: A Single-Center Retrospective Study
}

\author{
Putra Kurnia Nugraha ${ }^{1}$, Edward Kusuma ${ }^{2 *}$, \\ Soni Sunarso Sulistiawan ${ }^{3}$, Teuku Aswin Husain"
}

${ }^{1}$ Anesthesiologist; Department of Anesthesiology and Intensive Therapy;
Faculty of Medicine Universitas Airlangga; Dr Soetomo General Hospital, Surabaya, Indonesia

${ }^{2}$ Consultant of Intensive Care; Department of Anesthesiology and Intensive Therapy; Faculty of Medicine Universitas Airlangga; Dr Soetomo General Hospital, Surabaya, Indonesia

${ }^{3}$ Consultant of Pain Medicine; Department of Anesthesiology and Intensive Therapy; Faculty of Medicine Universitas Airlangga; Dr Soetomo General Hospital, Surabaya, Indonesia

${ }^{4}$ Consultant of Cardiovascular Anesthesia \& Intensive Care; Department of Anesthesiology and Intensive Therapy; Faculty of Medicine Universitas Airlangga; Dr Soetomo General

Hospital, Surabaya, Indonesia

*Corresponding author details: Edward Kusuma; edu.anest@gmail.com

\begin{abstract}
Background: Geriatric, obesity, and chronic disease are classified as risk factors for adverse outcomes of coronavirus disease 2019 (COVID-19). Studies regarding the importance of these comorbidities in COVID-19 with severe complications such as acute respiratory distress syndrome (ARDS) are scarce. This study aims to analyze age, obesity, and chronic disease comorbidities as risk factors for 28-days mortality in COVID-19 patients with ARDS.

Methods: A retrospective, single-center study was conducted in Dr. Soetomo General Hospital, Surabaya, Indonesia between July-October 2020. We included all adult inpatients ( $\geq 18$ years old) of confirmed COVID-19 with ARDS. Demographic, comorbidities, initial PaO2/FiO2 ratio, time of discharge or death were obtained from medical records and compared the ARDS severity between survivors and non-survivors. The univariate and multivariate logistic regression methods were used to identify risk factors associated with in-hospital death. Result: Among 102 patients of COVID-19 with ARDS, the median age is 52 years. Most of them are within 50 59 age categories. The median hospital length of stay (LOS) for survivor is 22 (15.7 - 26) days and 9 (4.25 $14.4)$ days for non-survivor. The 28-days mortality rate is $48(47.1 \%)$ patients. Age $>65$ years old $(\mathrm{HR}=2.7$, $95 \%$ CI $1.39-5.44$, p value $=0.004)$, obesity $(\mathrm{HR}=2.2,95 \%$ CI $1.16-4.51, \mathrm{p}$ value $=0.016)$, and chronic hypertension $(\mathrm{HR}=1.98,95 \%$ CI $1.11-3.52$, $\mathrm{p}$ value $=0.02)$ are the independent risk factors for 28-days mortality in COVID-19 with ARDS.

Conclusion: Geriatric, obesity, and chronic hypertension comorbidities are the risk factors for mortality of COVID-19 with ARDS complications.
\end{abstract}

Keywords: Geriatric; obesity; chronic disease; comorbidities; COVID-19; ARDS

\section{INTRODUCTION}

COVID-19 is a pandemic and worldwide healthcare primary problem. (1) It has a wide spectrum of clinical signs and symptoms. Most of them have mild symptoms, but severe cases can be fatal. (2) On May 28, 2020, the World Health Organization (WHO) received 5.593.631 confirmed cases of COVID-19 infection with a mortality rate of 353.334 cases in all countries. (3) As of May 24, 2020, Indonesia had 22.271 active cases with a total of 1.372 death cases and a cure rate of 5.402 cases. (4) The mortality rate in Indonesia is $6.16 \%$ and is the highest mortality rate in Southeast Asia. (5) In most cases, COVID-19 infection can have mild symptoms and heal on its own, but some have developed and caused complications such as respiratory failure, pulmonary edema, acute respiratory distress syndrome (ARDS), septic shock, and multiorgan dysfunction. (2) Severe cases can lead to acute respiratory hypoxemia and ARDS. ARDS is a lifethreatening complication of COVID-19 in critically ill patients. Patients with severe COVID-19 infection can develop symptoms and signs of respiratory failure, $42 \%$ of these patients can develop ARDS and about $61-81 \%$ require intensive care in the Intensive Care Unit (ICU). (6) The data on the clinical characteristics and outcomes of patients with severe ARDS complications are rare, but the most important is to reduce mortality. 
The COVID-19 pandemic has claimed many victims, especially in patients with confirmed COVID-19 accompanied by comorbidities such as older adults, diabetes, hypertension, chronic heart disease, kidney disease, cerebrovascular disease, respiratory disease, and others. (7) Since the assessed risk of mortality is quite high for a growing population as large as Indonesia and patients with different interventions in each case, therefore, it is necessary to obtain sufficient data evidence. Throughout this study, we assessed critically ill patients admitted to Dr. Soetomo General Hospital with confirmed COVID-19 pneumonia. This study's baseline data on COVID-19 comorbidity and mortality will be highly vital in evaluating who is at higher risk of becoming critically ill and who will most likely benefit from intensive care treatment.

\section{METHODS}

A single-center retrospective observational study was conducted in Dr. Soetomo General Hospital in Surabaya, Indonesia. The data were extracted from medical records of confirmed-COVID-19 patients who were admitted to High-care units and ICU of the hospital from July 2020 to October 2020. Adult patients with the age of $\geq 18$ years who have confirmed suffering COVID-19 through polymerase chain reaction (PCR) test, the $\mathrm{PaO} 2 / \mathrm{FiO} 2$ ratio $<300 \mathrm{mmHg}$ was included as inclusion criteria. We excluded the patients who have not been confirmed by PCR test and/or probable cases, pregnant patients, and, early discharge and/or incorporated patients. Identification of baseline characteristics, demographics, and underlying chronic disease was described. ARDS severity is based on the Berlin Definition of ARDS. (8) We obtained the Ethical Clearance of this study by The Clinical Research Unit of Ethical Committee in Health Research, Dr. Soetomo General Hospital, Surabaya Number 0009/KEPK/VI/2020. All participants of this study have signed the informed consent form.

Statistical analysis of this study was performed using the 26th version of the IBM Statistical Package for the Social Sciences (SPSS). The normality test is done by Kolmogorov-Smirnov test. The quantitative variables were presented as a median (interquartile range), categorical variables were presented as frequency (percentage). We compared the continuous variables using the T-test and Mann-Whitney test. Pearson Chi-Square test, Fisher exact test, and Kruskal Wallis test are performed to determine the differences in categorical variables. We used Cox proportional hazards modeling to assess the independent risk factor for 28-days mortality while adjusting for other covariates simultaneously.

\section{RESULT}

A total of 102 patients of confirmed-COVID-19 with ARDS complications were treated in ICU and High-care units. Their baseline characteristics are reported in Table 1 . The median age of the participants of this study is 52 years old and did not differ significantly across the ARDS severity group. Most of the participants with severe ARDS are male and within the 50-59 age group. There are 27 participants with normal Body Mass Index (BMI), 26 participants with overweight, and 11 obese patients with severe ARDS. Diabetes and chronic hypertension are the most underlying disease in the population. Eighteen participants with severe ARDS were not treated in ICU because of limited resources. The median of the initial $\mathrm{PaO} 2 / \mathrm{FiO} 2$ ratio was $79.6(58-137) \mathrm{mmHg}$. The mortality rate is $48(47.1 \%)$ patients who were classified as severe ARDS which is the highest mortality in both intensive and non-intensive care, totaling 41 patients.

The median age, age group, sex, weight, BMI were not statistically significant among the survivor and nonsurvivor groups.
Commordibities, geriatric, hypertension, admittance, and ARDS severity are related to 28-days mortality in COVID19 patients with ARDS according to the Pearson Chisquare test with a p-value of $0.005,0.011,0.006,0.022$, and 0.001 respectively (Table 2 ). The underlying comorbidities and other covariates were analyzed with Cox proportional hazards regression to determine the independent risk factor for 28-days mortality. Table 3 reported that age $>65$ years old with Hazard Ratio (HR) of 2.7, 95\% Confidence Interval (CI) of $1.39-5.44$, and a p-value of 0.004 . The obesity (HR= 2.2, 95\% CI $1.16-4.51$, p-value $=0.016)$, and chronic hypertension $(\mathrm{HR}=1.98,95 \%$ CI $1.11-3.52$, pvalue $=0.02$ ) are the independent risk factors for 28-days mortality in COVID-19 with ARDS respectively.

\section{DISCUSSION}

We report on 102 confirmed-COVID-19 patients with ARDS characterized by acute respiratory hypoxemia. Seven of moderate ARDS and 41 of severe ARDS patients had died at 28 days. Of all those who died, 33 (32.4\%) patients required ICU treatment, and $15(14.7 \%)$ died in a High-care unit setting because of the limited resources at that time. We observed that the age groups of COVID-19 patients with ARDS are above 50 years old. COVID-19 patients with ARDS accompanied by geriatric comorbidities had a 2.7 times greater risk of death than non-geriatric patients. Age factor, especially at age $>50$ years, there are several physiological changes in the immune system, including cell cytokine signaling function, nitric oxide and peroxide production, and decreased function of neutrophils (CD11b+Gr-1+ cells). Old age is susceptible to secondary infections, bacterial infections to sepsis, so it is closely related to a worse prognosis if you are critically ill. $(9,10)$ It is proved that the age is related to decreasing function of the immunity system and leads to worse outcomes. (11) According to prior studies, about $70 \%$ of COVID-19 infected patients were males. (12-14) Males and adults over the age of 65 are more likely to have ARDS than females or people of a younger age. $(15,16)$ Furthermore, in this study, males are the most number with severe ARDS and mortality in this study. A greater number of expressions of ACE- 2 receptors may be the cause. $(17,18)$

Most of the patients in this study had a normal BMI, followed by an overweight BMI, and a small proportion (19 patients) were obese. The median BMI was 25.9, the median weight was $70 \mathrm{~kg}$. This study found no significant difference in body weight and BMI when it was associated with the severity of ARDS. In contrast to studies in the United States, body weight and BMI profiles have differences in almost half of the study participants who are obese (> 50.8\%) with BMI 30. (19) In this study, COVID-19 patients with ARDS and obesity had a 2.2 times risk of dying compared to those without obesity. This is also similar in several other studies which state that there is a close correlation between high BMI and the risk of hospitalization, ICU care and mechanical ventilation, and the risk of death (19-21) The risk will increase progressively starting from BMI 25.9. (19) Obesity is a condition with small but prolonged chronic inflammation, it leads the body to produce more proinflammatory cytokines. Obesity is associated with other comorbidities such as diabetes, cardiovascular disease and is strongly related to worse outcomes in severe COVID-19 cases. $(13,20,21)$

Comorbid chronic disease is a risk factor in COVID-19 patients with ARDS. The most common comorbid diseases were diabetes (46 patients) and hypertension (33 patients), and most patients had at least one type of comorbidity. The results of this study are similar to a study that stated that the prevalence of diabetes was high in COVID-19 patients, but differed in terms of mortality. (22) 
Diabetics are susceptible and are associated with a high risk of mortality from COVID-19 infection. The causes include an increase in pro-inflammatory cytokines, a decrease in anti-inflammatory cytokines, a decrease in the activity of Natural Killer (NK) Cells due to high blood sugar exposure, disturbances in the glutathione (GSH) system so that Reactive oxygen species (ROS) increases, and decreases the function of macrophages. However, according to this research, diabetes was not significantly associated with the incidence of patient mortality.

Hypertension is reported as a risk factor for worse outcomes in COVID-19 because greater ACE-2 was expressed in the body. (23-25) This study also reports that COVID-19 patients with ARDS who have comorbid hypertension have a 1.9 times risk of death compared to patients without hypertension. Several other studies have shown the same thing, that hypertension increases the risk of death by 7.4 times and most of the non-survivors of COVID-19 are hypertensive patients. $(14,26)$ Clinical deterioration in COVID-19 patients with hypertension is due to an increase in ACE-2 receptor expression so that COVID-19 patients with hypertension are more susceptible to infection and have a faster clinical deterioration. (17)

Severe ARDS was a complication that occurred in most of the study participants (64 patients) with a median $\mathrm{P} / \mathrm{F}$ ratio of 79.6, and most of them were treated in intensive care (58 patients), and 48 patients died (47.1\%). The average LOS in the hospital in this study was 16 days or with a median of 16.5 days. The most common causes of ARDS, sepsis, and other complications of organ failure in COVID-19 are cytokine storms and severe immune injury. This cytokine storm is closely related to an increase in proinflammatory cytokines in the body. The pro-inflammatory cytokines IL1b, IFN $\gamma$, IP10, and MCP1, and the antiinflammatory cytokines IL4 and IL10 were found to be elevated in COVID-19 patients. (12)

COVID-19 patients with severe ARDS have a high mortality rate, recorded 46 patients (45.1\%) in intensive care and 18 patients $(17.6 \%)$ in non-intensive care died. Not all patients with severe ARDS received intensive care, and some died in non-intensive care. This is due to limited space in intensive care. The limitation of this study is that the data collection for COVID-19 patients with ARDS was done through secondary data from medical records, and was carried out retrospectively. This does not represent the trend of the $\mathrm{P} / \mathrm{F}$ ratio or the existence of a worsening trend in the following days.

\section{CONCLUSION}

Comorbidity is indeed a risk factor that exacerbates COVID-19 patients with ARDS. Geriatric factors or adults aged > 65 years, obesity, and chronic hypertension are independent risk factors for the incidence of 28-day mortality in COVID-19 with ARDS. Adult people with a history of these comorbidities can be more vigilant because they are a vulnerable group. Complete Covid-19 vaccination and implementation of Health protocols need to be maintained to reduce the risk of exposure. In addition, it is important to conduct further research covering a larger number of research participants, in a longer period, and involving other teaching hospitals. Furthermore, this study can be used as a reference for the profile of COVID-19 patients with ARDS in Indonesia.

\section{REFERENCES}

[1] Lu H, Stratton CW, Tang YW. Outbreak of pneumonia of unknown etiology in Wuhan, China: The mystery and the miracle. Journal of medical virology. 2020;92(4):401.
[2] Sohrabi C, Alsafi Z, O'Neill N, Khan M, Kerwan A, AlJabir A, et al. World Health Organization declares global emergency: A review of the 2019 novel coronavirus (COVID-19). International journal of surgery. 2020; 76:71-6.

[3] World Health O. WHO Coronavirus Disease (COVID19) Dashboard| WHO Coronavirus Disease (COVID19) Dashboard. 2021.

[4] World Health O. Coronavirus disease (COVID-19): weekly epidemiological, update 1, 17 August 2020. 2020.

[5] Livingston E, Bucher K, Rekito A. Coronavirus disease 2019 and influenza 2019-2020. Jama. 2020;323(12):1122-.

[6] Gibson PG, Qin L, Puah SH. COVID-19 acute respiratory distress syndrome (ARDS): clinical features and differences from typical pre-COVID-19 ARDS. Medical Journal of Australia. 2020;213(2):54-6.

[7] Biswas M, Rahaman S, Biswas TK, Haque Z, Ibrahim B. Association of sex, age, and comorbidities with mortality in COVID-19 patients: a systematic review and meta-analysis. Intervirology. 2021;64(1):36-47.

[8] Force ADT, Ranieri VM, Rubenfeld GD, Thompson BT, Ferguson N, Caldwell E, et al. Acute respiratory distress syndrome. Jama. 2012;307(23):2526-33.

[9] Guan W-j, Ni Z-y, Hu Y, Liang W-h, Ou C-q, He J-x, et al. Clinical characteristics of coronavirus disease 2019 in China. New England journal of medicine. 2020;382(18):1708-20.

[10] Nikolich-Žugich J. The twilight of immunity: emerging concepts in aging of the immune system. Nature immunology. 2018;19(1):10-9.

[11] Brown R, McKelvey MC, Ryan S, Creane S, Linden D, Kidney JC, et al. The Impact of Aging in Acute Respiratory Distress Syndrome: A Clinical and Mechanistic Overview. Frontiers in Medicine. 2020;7.

[12] Huang C, Wang Y, Li X, Ren L, Zhao J, Hu Y, et al. Clinical features of patients infected with 2019 novel coronavirus in Wuhan, China. Lancet (London, England). 2020;395(10223):497-506.

[13] Clinical characteristics and day-90 outcomes of 4244 critically ill adults with COVID-19: a prospective cohort study. Intensive Care Med. 2021;47(1):60-73.

[14] Zhou F, Yu T, Du R, Fan G, Liu Y, Liu Z, et al. Clinical course and risk factors for mortality of adult inpatients with COVID-19 in Wuhan, China: a retrospective cohort study. Lancet (London, England). 2020;6736(20):1-9.

[15] Jin J-M, Bai P, He W, Wu F, Liu X-F, Han D-M, et al. Gender differences in patients with COVID-19: focus on severity and mortality. Frontiers in public health. 2020; 8:152.

[16] Peckham H, de Gruijter NM, Raine C, Radziszewska A, Ciurtin C, Wedderburn LR, et al. Male sex identified by global COVID-19 meta-analysis as a risk factor for death and ITU admission. Nature communications. 2020;11(1):1-10.

[17] Cai H. Sex difference and smoking predisposition in patients with COVID-19. The Lancet Respiratory Medicine. 2020;8(4):e20. 
[18] Klein SL, Flanagan KL. Sex differences in immune responses. Nature Reviews Immunology. 2016;16(10):626-38.

[19] Kompaniyets L, Goodman AB, Belay B, Freedman DS, Sucosky MS, Lange SJ, et al. Body mass index and risk for COVID-19-related hospitalization, intensive care unit admission, invasive mechanical ventilation, and death-united states, march-december 2020. Morbidity and Mortality Weekly Report. 2021;70(10):355.

[20] Anderson MR, Geleris J, Anderson DR, Zucker J, Nobel YR, Freedberg D, et al. Body mass index and risk for intubation or death in SARS-CoV-2 infection: a retrospective cohort study. Annals of internal medicine. 2020;173(10):782-90.

[21] Tartof SY, Qian L, Hong V, Wei R, Nadjafi RF, Fischer $\mathrm{H}$, et al. Obesity and mortality among patients diagnosed with COVID-19: results from an integrated health care organization. Annals of internal medicine. 2020;173(10):773-81.
[22] Singh AK, Gupta R, Ghosh A, Misra A. Diabetes in COVID-19: Prevalence, pathophysiology, prognosis and practical considerations. Diabetes \& Metabolic Syndrome: Clinical Research \& Reviews. 2020;14(4):303-10.

[23] Fang L, Karakiulakis G, Roth M. Are patients with hypertension and diabetes mellitus at increased risk for COVID-19 infection? [Published correction appears in Lancet Respir Med 8: e54, 2020]. Lancet Respir Med.; 2020. p. e21.

[24] Hamet P, Pausova Z, Attaoua R, Hishmih C, Haloui M, Shin J, et al. SARS-CoV-2 Receptor ACE2 Gene Is Associated with Hypertension and Severity of COVID 19: Interaction with Sex, Obesity, and Smoking. American Journal of Hypertension. 2021;34(4):367-76.

[25] Wu C, Chen X, Cai Y, Zhou X, Xu S, Huang H, et al. Risk factors associated with acute respiratory distress syndrome and death in patients with coronavirus disease 2019 pneumonia in Wuhan, China. JAMA internal medicine. 2020;180(7):934-43.

[26] Caramelo F, Ferreira N, Oliveiros B. Estimation of risk factors for COVID-19 mortality-preliminary results. MedRxiv. 2020.

TABLE 1: Baseline Characteristic of the Participants Based on ARDS Severity

\begin{tabular}{|c|c|c|c|c|}
\hline \multirow{2}{*}{ Variables } & \multicolumn{3}{|c|}{ ARDS Severity } & \multirow{2}{*}{ p-value ${ }^{a b}$} \\
\hline & Mild (n=8) & Moderate $(n=30)$ & Severe $(n=64)$ & \\
\hline Age (years) & $52.38( \pm 13.1)$ & $49.87( \pm 13.3)$ & $52.56( \pm 11.3)$ & $0.774^{\mathrm{a}}$ \\
\hline Age Categories (years old), n (\%) & & & & $0.630^{\mathrm{b}}$ \\
\hline $18-29$ & $0(0)$ & $4(13.3)$ & $2(3.1)$ & \\
\hline $30-39$ & $1(12.5)$ & $2(6.7)$ & $4(6.3)$ & \\
\hline $40-49$ & $1(12.5)$ & 7 (23.3) & $16(25)$ & \\
\hline $50-59$ & $5(62.5)$ & $10(33.3)$ & $26(40.6)$ & \\
\hline $60-69$ & $0(0)$ & $5(16.7)$ & $11(17.2)$ & \\
\hline$\geq 70$ & $1(12.5)$ & $2(6.7)$ & $5(7.8)$ & \\
\hline Sex & & & & $0.114^{\mathrm{b}}$ \\
\hline Male & $3(37.5)$ & $18(60)$ & $46(71.9)$ & \\
\hline Female & $5(62.5)$ & $12(40)$ & $18(28.1)$ & \\
\hline Weight (kg) & $\begin{array}{c}62.5 \\
(58.5-73.7)\end{array}$ & $\begin{array}{c}69 \\
(60-80)\end{array}$ & $\begin{array}{c}70 \\
(62.5-80)\end{array}$ & 0.469 a \\
\hline BMI & $\begin{array}{c}24.7 \\
(22.7-27.2)\end{array}$ & $\begin{array}{c}27.1 \\
(22.4-29.7)\end{array}$ & $\begin{array}{c}25.9 \\
(23.4-29.3)\end{array}$ & 0.657 a \\
\hline Normal & $5(62.5)$ & $11(10.8)$ & $27(26.4)$ & $0.693^{\mathrm{b}}$ \\
\hline Overweight & $2(25)$ & $12(11.8)$ & $26(25.5)$ & $0.691^{b}$ \\
\hline Obesity & $1(12.5)$ & 7 (6.9) & $11(10.8)$ & $0.698^{b}$ \\
\hline Comorbidities & & & & $0.504^{b}$ \\
\hline None & $3(2.9)$ & $9(8.8)$ & $14(13.7)$ & \\
\hline Had at least 1 & $3(2.9)$ & 10 & 27 & \\
\hline Had at least 2 & $2(2)$ & 11 & $23(22.5)$ & \\
\hline Geriatric & & & & $0.757 \mathrm{~b}$ \\
\hline Yes & $1(12.5)$ & $3(10)$ & $10(15.6)$ & \\
\hline No & $7(87.5)$ & $27(90)$ & $54(84.4)$ & \\
\hline Diabetes & & & & $0.943^{\mathrm{b}}$ \\
\hline Yes & $4(50)$ & $13(43.3)$ & $29(45.3)$ & \\
\hline No & $4(50)$ & $17(56.7)$ & 35 (54.7) & \\
\hline Hypertension & & & & 0.897 \\
\hline Yes & $2(25)$ & $10(33.3)$ & $21(32.8)$ & \\
\hline No & $6(75)$ & $20(66.7)$ & $43(67.2)$ & \\
\hline Cardiovascular disease & & & & $0.734^{b}$ \\
\hline Yes & $0(0)$ & $2(6.7)$ & $3(4.7)$ & \\
\hline No & $8(100)$ & $28(93.3)$ & $61(95.3)$ & \\
\hline Chronic lung disease & & & & $0.760^{\mathrm{b}}$ \\
\hline Yes & $0(0)$ & $2(6.7)$ & $4(6.3)$ & \\
\hline No & $8(100)$ & $28(93.3)$ & $60(93.8)$ & \\
\hline
\end{tabular}




\begin{tabular}{|c|c|c|c|c|}
\hline Chronic kidney disease & & & & $0.776^{\mathrm{b}}$ \\
\hline Yes & $0(0)$ & $1(3.3)$ & $1(1.6)$ & \\
\hline No & $8(100)$ & $29(96.7)$ & $63(98.4)$ & \\
\hline Initial $\mathrm{PaO2} / \mathrm{FiO2}$ ratio & $\begin{array}{c}258.3 \\
(213.7-283.3)\end{array}$ & $\begin{array}{c}147 \\
(118.1-173.9)\end{array}$ & $\begin{array}{c}67.9 \\
(54-78.1)\end{array}$ & $<0.001^{\mathrm{a}}$ \\
\hline Hospital Admittance & & & & $0.035^{b}$ \\
\hline Not referred & $5(62.5)$ & $11(36.7)$ & $14(21.9)$ & \\
\hline $\begin{array}{l}\text { Referred from another } \\
\text { hospital }\end{array}$ & $3(37.5)$ & $19(63.3)$ & $50(78.1)$ & \\
\hline Admittance & & & & $<0.001^{b}$ \\
\hline ICU & $0(0)$ & $12(40)$ & $46(71 . .9)$ & \\
\hline High-care unit & $8(100)$ & $18(60)$ & $18(28.1)$ & \\
\hline 28-days Mortality & & & & $<0.001^{b}$ \\
\hline Survivor & $8(100)$ & $23(76.7)$ & $23(35.9)$ & \\
\hline Non-survivor & $0(0)$ & $7(23.3)$ & $41(64.1)$ & \\
\hline Hospital Length of Stay & $\begin{array}{c}20.5 \\
(12-28)\end{array}$ & $\begin{array}{c}17 \\
(9-22)\end{array}$ & $\begin{array}{c}14.5 \\
(6-24)\end{array}$ & $0.327^{a}$ \\
\hline
\end{tabular}

a : Kruskal-Wallis test, $p$-value $<0.05$ was significantly different

b : Pearson Chi-square test, $p$-value $<0.05$ was viewed as a significantly different

TABLE 2 : Characteristics of the Participants Based on 28-days Mortality

\begin{tabular}{|c|c|c|c|}
\hline \multirow{2}{*}{ Variables } & \multicolumn{2}{|c|}{ 28-days Mortality } & \multirow{2}{*}{ p-value ab } \\
\hline & Survivor $(n=54)$ & Non-survivor $(n=48)$ & \\
\hline Age (years) & $50.13( \pm 11.14)$ & $53.58( \pm 12.88)$ & $0.321^{\mathrm{a}}$ \\
\hline Age Categories (years old), n (\%) & & & $0.142^{\mathrm{b}}$ \\
\hline $18-29$ & $4(7.4)$ & $2(4.2)$ & \\
\hline $30-39$ & $5(9.3)$ & $2(4.2)$ & \\
\hline $40-49$ & $11(20.4)$ & $13(27.1)$ & \\
\hline $50-59$ & $25(46.3)$ & $16(33.3)$ & \\
\hline $60-69$ & $8(14.8)$ & $8(16.7)$ & \\
\hline$\geq 70$ & $1(1.9)$ & $7(14.6)$ & \\
\hline Sex & & & $0.147^{b}$ \\
\hline Male & $32(59.3)$ & $35(72.9)$ & \\
\hline Female & $22(40.7)$ & $13(27.1)$ & \\
\hline Weight (kg) & $69(60-75)$ & $70(60-80)$ & 0.500 a \\
\hline BMI & $25.71(23.3-27.9)$ & $27.1(23-30.7)$ & $0,234^{\text {a }}$ \\
\hline Normal & $24(44.4)$ & $19(39.5)$ & $0.225^{b}$ \\
\hline Overweight & $23(42.6)$ & $17(35.5)$ & $0.459^{b}$ \\
\hline Obesity & $7(13)$ & $12(25)$ & $0.119^{b}$ \\
\hline Comorbidities & & & $0.005^{b}$ \\
\hline None & $20(37)$ & $6(12.5)$ & \\
\hline Had at least 1 & $24(44.4)$ & $16(33.3)$ & \\
\hline Had at least 2 & $10(18.6)$ & $26(54.2)$ & \\
\hline Geriatric & & & $0.011^{b}$ \\
\hline Yes & $3(5.6)$ & $11(22.9)$ & \\
\hline No & $51(94.4)$ & $37(77.1)$ & \\
\hline Diabetes & & & $0.181^{b}$ \\
\hline Yes & $21(38.9)$ & $25(52.1)$ & \\
\hline No & $33(61.1)$ & $23(47.9)$ & \\
\hline Hypertension & & & $0.006^{b}$ \\
\hline Yes & $11(20.4)$ & $22(45.8)$ & \\
\hline No & $43(79.6)$ & $26(54.2)$ & \\
\hline Cardiovascular disease & & & $0.746^{\mathrm{b}}$ \\
\hline Yes & $3(5.6)$ & $2(4.2)$ & \\
\hline No & $51(94.4)$ & $46(95.8)$ & \\
\hline Chronic lung disease & & & $0.321^{\mathrm{b}}$ \\
\hline Yes & $2(3.7)$ & $4(8.3)$ & \\
\hline No & $52(96.3)$ & $44(91.7)$ & \\
\hline Chronic kidney disease & & & $0.130^{\mathrm{b}}$ \\
\hline Yes & $0(0)$ & $2(4.2)$ & \\
\hline No & $54(100)$ & $46(95.8)$ & \\
\hline Initial $\mathrm{PaO2} / \mathrm{FiO2}$ ratio & $113.92(78.12-173.9)$ & $60.5(54-79.9)$ & $<0.001^{\mathrm{a}}$ \\
\hline ARDS Severity & & & $<0.001^{b}$ \\
\hline Mild & $8(14.8)$ & $0(0)$ & \\
\hline Moderate & $23(42.6)$ & $7(14.6)$ & \\
\hline Severe & $23(42.6)$ & $41(85.4)$ & \\
\hline
\end{tabular}




\begin{tabular}{lccc}
\hline Hospital Admittance & & & $0.627^{\mathrm{b}}$ \\
$\quad$ Not referred & $17(31.5)$ & $13(27.1)$ & \\
$\quad$ Referred from another hospital & $37(68.5)$ & $35(72.9)$ & \\
Admittance & & $33(68.8)$ & $<\mathbf{0 . 0 2 2}^{\mathbf{b}}$ \\
$\quad$ ICU & $25(46.3)$ & $15(31.3)$ & \\
$\quad$ High-care unit & $29(53.7)$ & $9(4.25-14.5)$ & $\mathbf{< 0 . 0 0 1}^{\mathbf{a}}$ \\
Hospital Length of Stay & $22(15.75-26)$ & & \\
\hline
\end{tabular}

a : Mann-Whitney test, $p$-value $<0.05$ was significantly different

b : Pearson Chi-square test, $p$-value $<0.05$ was viewed as a significantly different

TABLE 3: Cox Proportional Hazards Regression of ROX Index Predicting Intubation and 28-Days Mortality

\begin{tabular}{|c|c|c|c|c|}
\hline Variable & HR & Corr. Coefficient & $95 \% \mathrm{CI}$ & p-value* \\
\hline Sex & - & - & - & 0.056 \\
\hline $\begin{array}{l}\text { Age }>65 \text { years } \\
\text { (geriatric) }\end{array}$ & 2.753 & 1.013 & $1.392-5.446$ & 0.004 \\
\hline Overweight & - & - & - & 0.752 \\
\hline Obesity & 2.291 & 0.829 & $1.164-4.511$ & 0.016 \\
\hline Diabetes & - & - & - & 0.388 \\
\hline Hypertension & 1.981 & 0.684 & $1.115-3.520$ & 0.020 \\
\hline Chronic kidney disease & - & - & - & 0.818 \\
\hline Chronic lung disease & - & - & - & 0.249 \\
\hline Cardiovascular disease & - & - & - & 0.876 \\
\hline
\end{tabular}

* Cox proportional hazards regression forward likelihood ratio (LR) test 